\title{
Expression of Multidrug Resistance ATP-Binding Cassette (ABC) Transporters in Canine Mammary Tumors
}

\author{
Breno S. Salgado ${ }^{1,2 *}$, Suely Nonogaki ${ }^{3}$, Luisa M. Soares ${ }^{4}$, Angela Akamatsu ${ }^{5}$, \\ Cristiano R. N. da Silva ${ }^{5}$, Thiago P. Anacleto5, Rodolfo Malagós, Rafael M. Rocha ${ }^{3}$, \\ Fátima Gärtner' ${ }^{2}$, Noeme S. Rocha ${ }^{1,4}$ \\ ${ }^{1}$ Departamento de Patologia, Faculdade de Medicina de Botucatu, Universidade Estadual Paulista, Campus de \\ Botucatu, Botucatu, Brazil \\ ${ }^{2}$ Instituto de Ciências Biomédicas Abel Salazar, Universidade do Porto (Intitute of Biomedical Sciences Abel \\ Salazar of University of Porto), Oporto, Portugal \\ ${ }^{3}$ Fundação Antônio Prudente, Hospital A.C. Camargo, São Paulo, Brazil \\ ${ }^{4}$ Departamento de Clínica Veterinária, Faculdade de Medicina Veterinária e Zootecnia, Universidade Estadual \\ Paulista, UNESP, . Botucatu, Brazil \\ ${ }^{5}$ Hospital Escola de Medicina Veterinária, Fundação de Ensino e Pesquisa de Itajubá-FEPI, Itajubá, Brazil \\ Email: brenosalgado@globo.com
}

Received 29 June 2015; accepted 26 July 2015; published 29 July 2015

Copyright (C) 2015 by authors and Scientific Research Publishing Inc.

This work is licensed under the Creative Commons Attribution International License (CC BY). http://creativecommons.org/licenses/by/4.0/

c) (i) Open Access

\section{Abstract}

Mammary neoplasms are the most common tumors in female dogs. They are usually treated using solely surgical mastectomy - which is recognized as unsatisfactory in many cases. Given this, the benefits of chemotherapy in dogs with mammary cancer need to be further explored. Some drugs that can be used for treating canines with mammary tumors may be substrates of uptake and/or efflux transporters such as the ATP-binding cassette (ABC) transporters. Unfortunately, very little is known regarding the pathobiology of such proteins in canine tumors, including mammary cancer. Accordingly, this study was designed to characterize the expression of $A B C$ transporters $P$ glycoprotein, MRP1, and MRP2 and their relation with clinicopathologic factors in order to allow a better understanding of their influence in canine mammary cancer. P-glycoprotein was expressed in tumors from $55.8 \%$ of patients, while MRP1 and MRP2 were expressed in $37.2 \%$ and $39.5 \%$ of tumors, respectively. P-glycoprotein expression showed to be related with regional lymph node spread $(P=0.0038)$, as well as with tumor grade $(P=0.0353)$ and with a shorter survival $(P=$ $0.0245)$. MRP1 revealed a strong association with a higher histological grade $(P<0.0001)$ and overall survival $(P=\mathbf{0 . 0 0 0 2})$. Additionally, MRP1 was determined as prognostic indicator independent of lymph node status using Cox proportional-hazards regression multivariate analysis (P

*Corresponding author.

How to cite this paper: Salgado, B.S., Nonogaki, S., Soares, L.M., Akamatsu, A., da Silva, C.R.N., Anacleto, T.P., Malagó, R., Rocha, R.M., Gärtner, F. and Rocha, N.S. (2015) Expression of Multidrug Resistance ATP-Binding Cassette (ABC) Transporters in Canine Mammary Tumors. Advances in Breast Cancer Research, 4, 77-85.

http://dx.doi.org/10.4236/abcr.2015.43009 
$=0.0216$ ). No relations between MRP2 and clinicopathologic features were observed. We have found that P-glycoprotein and MRP1 are expressed in highly aggressive canine mammary tumors and are related with poor prognosis. Our results suggest that they may play a significant role in the course of canine mammary cancer progression and be promising candidate markers for a validation study on therapy outcome.

\section{Keywords}

MDR1, P-Gp, MRP1, MRP2, ABCC2, Mammary Neoplasms, Prognosis, Dog

\section{Introduction}

Mammary tumors represent the most common neoplasm in intact female dogs and approximately half are considered as malignant. Canine mammary carcinomas (CMCs) have heterogeneous features that make it difficult to determine patient prognosis [1] [2]. Studies regarding mammary tumors in dogs aimed at defining a more precise prognosis by evaluating different tumor characteristics such as oncogenes/oncoproteins [3] [4] and tumor growth or suppression related features [5] [6]. However, despite the many achievements regarding the understanding of CMCs pathobiology, much remains unknown.

Treatment for canine mammary tumors usually is restricted to surgical mastectomy - which is recognized as unsatisfactory in many cases [2]. However, there are neither studies with large case series that prove the benefits of chemotherapy for canine cancer nor consensus on which drugs must or may be used. Since different individuals with a similar disease may present different responses to the same drugs due to individual aspects, it is important to understand which cellular components of tumor cells can interfere in drug response. In humans, much has been learned about ATP-binding cassette (ABC) transporters, with different cancers presenting with alterations in such cellular components, leading to failure of cancer chemotherapy [7]-[11]. Initially discovered as chemotherapeutic drug-efflux pumps, ATP-binding cassette (ABC) superfamily of transporters represents the largest family of transmembrane proteins [9]. ABC transporters facilitate translocation of heterogeneous substrates including metabolic products, lipids and sterols, peptides and proteins, saccharides, amino acids, inorganic and organic ions, metals, and drugs across the membrane by using energy from ATP hydrolysis [12].

Since the concept of personalized medicine is being progressively applied to veterinary medicine, we can expect that $\mathrm{ABC}$ superfamily members may be increasingly evaluated in small animal oncology in a near future in order to promote a more accurate treatment. However, it is not widely understood whether ABC superfamily members have an influence on canine mammary tumors' pathobiology. Additionally, MRP2 expression was not previously evaluated in canine mammary cancer. Accordingly, in this study we aimed to evaluate the immunoexpression of $\mathrm{ABC}$ superfamily members in CMCs in order to address their potential prognostic implications in such tumors.

\section{Materials and Methods}

\subsection{Patients}

A prospective series of 43 cases of primary canine mammary tumors in adult females presenting from 2011 to 2013 was used. Surgical specimens were fixed in 10\% neutral buffered formalin and embedded in paraffin wax. Sections ( $3 \mu \mathrm{m}$ thick) were obtained and stained with hematoxylin and eosin (HE) for histological examination.

\subsection{Follow-Up}

Patients were followed up for a period of 18 months and overall survival was taken as the time (in months) from the date of the primary surgical treatment to the time of death.

\subsection{Histopathological Evaluation}

Tumors were classified according to the World Health Organization (WHO) criteria for canine mammary neoplasms [1]. Histological grade [13] and lymph node status were also evaluated. 


\subsection{Immunohistochemistry}

For ABC transporter proteins, $3 \mu \mathrm{m}$ thick histologic sections were obtained, deparaffinized, and rehydrated. Immunohistochemistry was performed by using a polymeric labeling detection system (Novolink Polymer Detection System, Novocastra Laboratories, Newcastle, UK). Antigen retrieval was carried out by heat treatment in $10 \mathrm{mM}$ citrate buffer $\mathrm{pH} 6.0$ for all primary antibodies. Subsequent endogen peroxidase and protein blockages were performed according manufacturers' instructions. All slides were then overnight incubated at $4^{\circ} \mathrm{C}$ with the specific primary antibodies. Then, the slides were immersed with the detection systems following the manufacturer's instructions. Subsequently, 3, 3' diaminobenzidine tetrahydrochloride (DAB) was used as chromogen in order to allow the visualization of antigen-antibody reaction. Slides were counterstained using Harris's hematoxylin, dehydrated, and mounted for evaluation and light microscopy. Antibodies data are presented at Table 1. All series included know positive cases as positive controls. Negative controls included replacement of the primary antibodies with non-reacting antibodies of the same subclass.

Samples were defined as positive when more than $10 \%$ of cells revealed immunoreactivity. Slides were evaluated by two independent observers blinded to patient characteristics and outcome. All cases with discrepant results were discussed during observation with a double-headed microscope, and a consensus was reached.

\subsection{Statistical Analysis}

Associations between the expression of the different ABC superfamily proteins and with clinicopathologic features were assessed by using Fisher's exact text when compared variables had exactly two groups $(2 \times 2$ contingency tables), such as LN status (positive or negative), and by using the $\mathrm{X}^{2}$ test for categorical variables such as histological grade and tumor histotype. Survival curves were estimated using Kaplan-Meier product-limit method, and the significance of differences between survival curves was determined using the log rank test. Multivariate analysis was performed by Cox proportional hazards regression modeling. All statistical tests were two sided, and statistical significance was accepted at the $\mathrm{P}<0.05$ level. All analyses were performed using the Prism GraphPad software version 5.0 (San Diego, CA).

\section{Results}

P-glycoprotein (Figure 1) and MRP1 (Figure 2) expression was mainly membranous but frequently associated with cytoplasmic positivity, whereas MRP2 expression was weak and mainly cytoplasmic. In all cases they were consistently expressed by luminal mammary cells (Figure 3). No associations were observed between ABC transporters and tumor histotype. A positive association between $\mathrm{P}$-glycoprotein and lymph node status $(\mathrm{P}=$ 0.0038) was found, as well as with tumor grade $(\mathrm{P}=0.0353)$. MRP1 revealed a strong association with a higher histological grade $(\mathrm{P}<0.0001)$. No relations between MPR2 and clinicopathologic features were observed. Results regarding tumor types, histological grade, and lymph node status according to P-glycoprotein, MRP1, and MRP2 expression are summarized in Table 2.

\section{Association between ABC Transporters and Survival}

Overall patient survival rates were determined using the log rank test with respect to expression of $\mathrm{ABC}$ transporters. P-glycoprotein was found to be significantly associated with a poor outcome $(\mathrm{P}=0.0245)$ (Figure 4(a)), as well as MRP1 ( $\mathrm{P}=0.0002)$ (Figure 4(b)). However, no significant difference in patient outcome was found with respect to MRP2 (Figure 4(c)) $(\mathrm{P}=0.2548)$. Additionally, MRP1 was determined as prognostic indicator independent of lymph node status using Cox proportional-hazards regression multivariate analysis $(\mathrm{P}=0.0216)$.

Table 1. Primary antibodies used for ABC superfamily immunohistochemistry.

\begin{tabular}{ccccc}
\hline Antibody & Source & Manufacturer & Dilution & Clone \\
\hline P-glycoprotein & Mouse & Dako & $1: 100$ & C494 \\
MRP1 & Mouse & Enzo LifeScience & $1: 200$ & MRPm6 \\
MRP2 & Mouse & Enzo LifeScience & $1: 200$ & M $_{2}$ III-6 \\
\hline
\end{tabular}

MRP1, multidrug resistance-associated protein 1; MRP2, multidrug resistance-associated protein 2. 


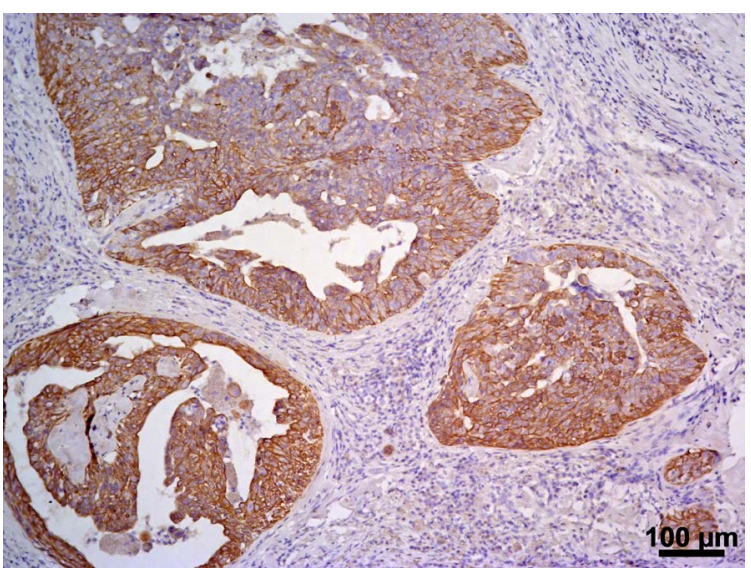

Figure 1. Canine mammary gland carcinoma revealing expression of $\mathrm{ABC}$ transporters. (A) Note the P-glycoprotein expression in luminal cells across the membrane and slighter in the cytoplasm (DAB immunohistochemistry, Harris hematoxylin counterstain).

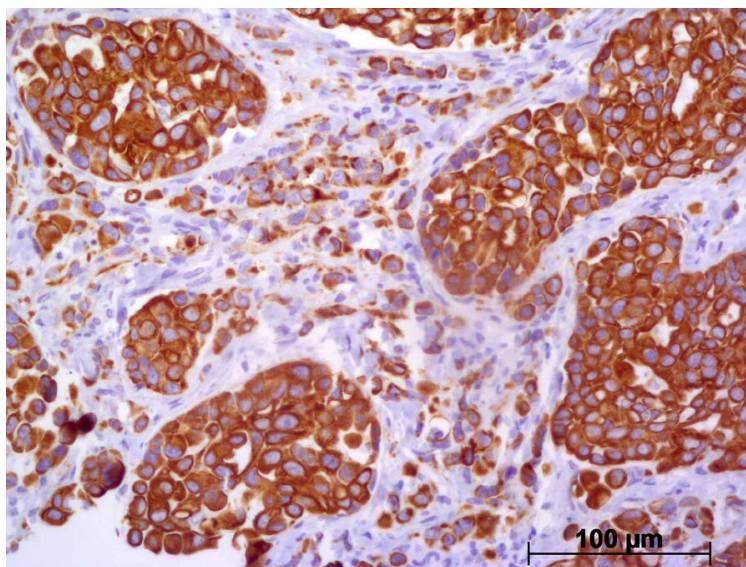

Figure 2. MRP1 strong expression in a mammary tumor with membrane and cytoplasm intense reactivity in canine mammary carcinoma (DAB immunohistochemistry, Harris hematoxylin counterstain).

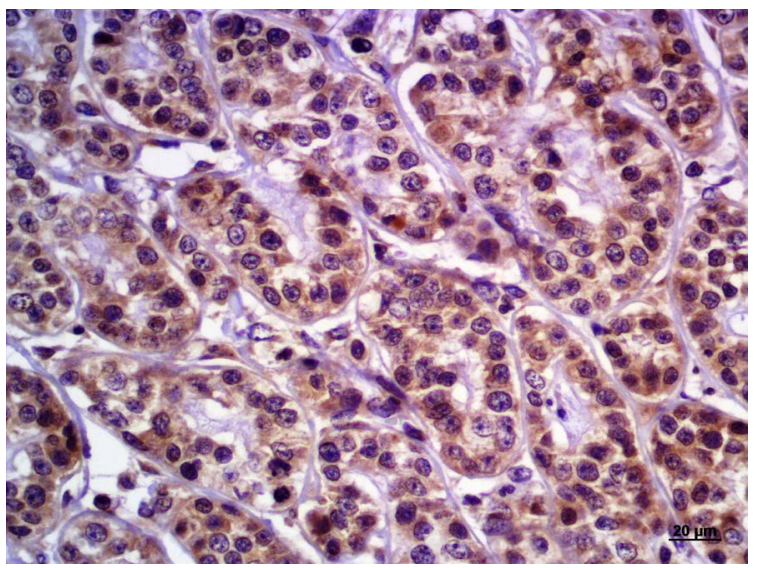

Figure 3. MRP2 expression mainly in the cytoplasm of mammary luminal cells in mammary carcinomas (DAB immunohistochemistry, Harris hematoxylin counterstain). 


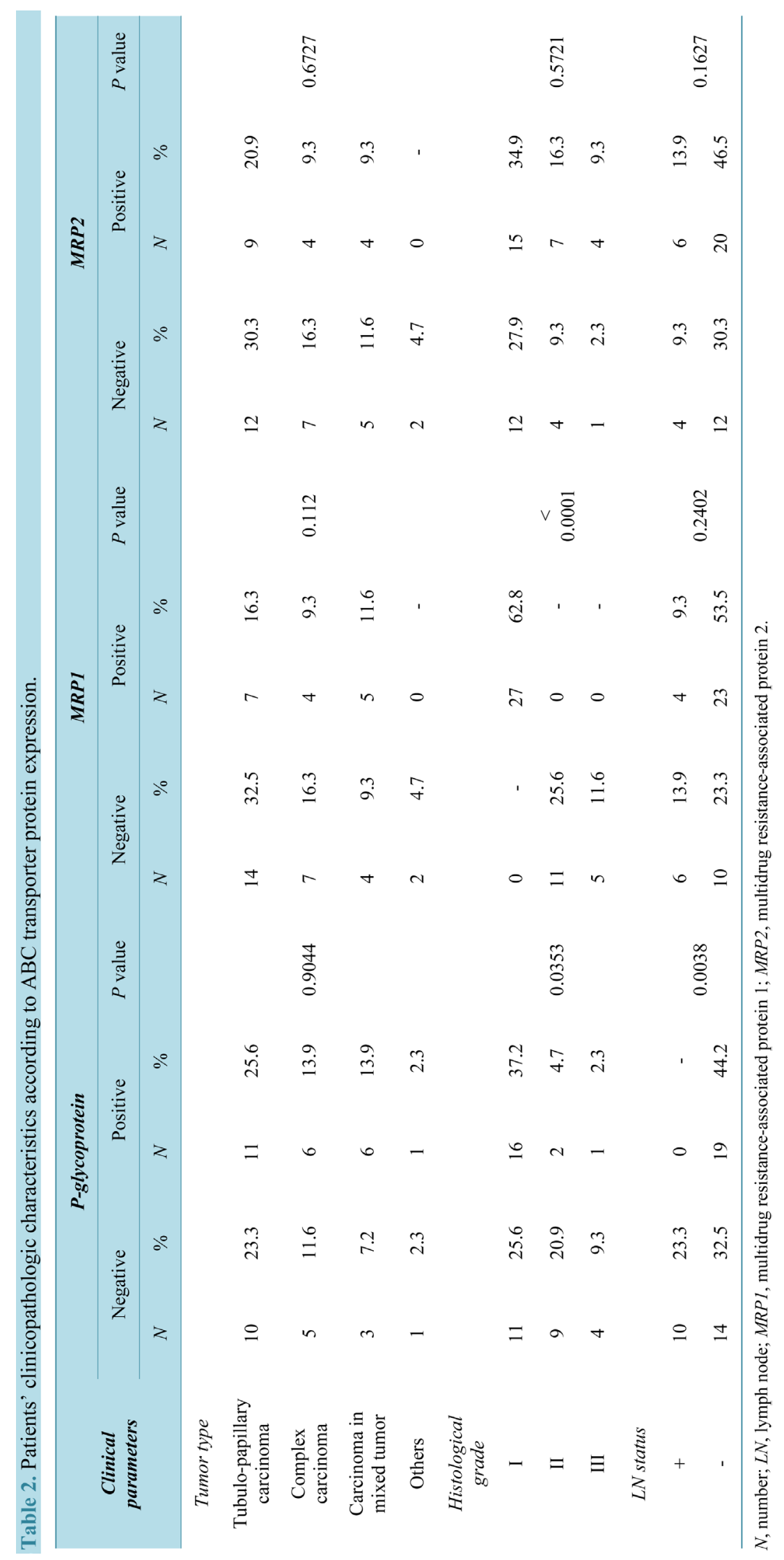




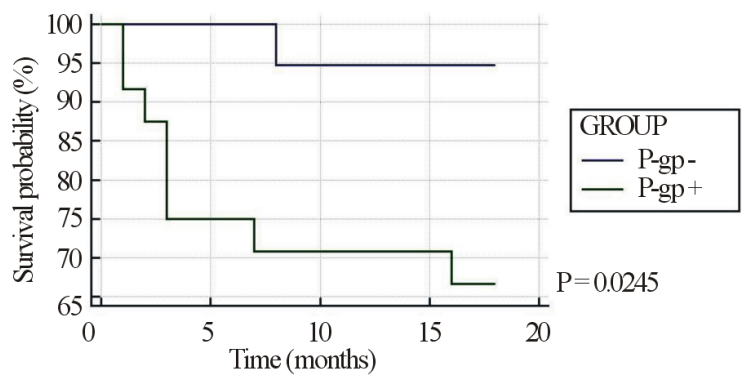

(a)

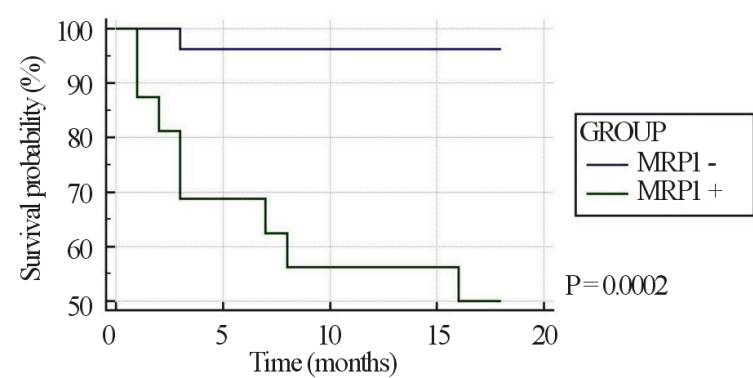

(b)

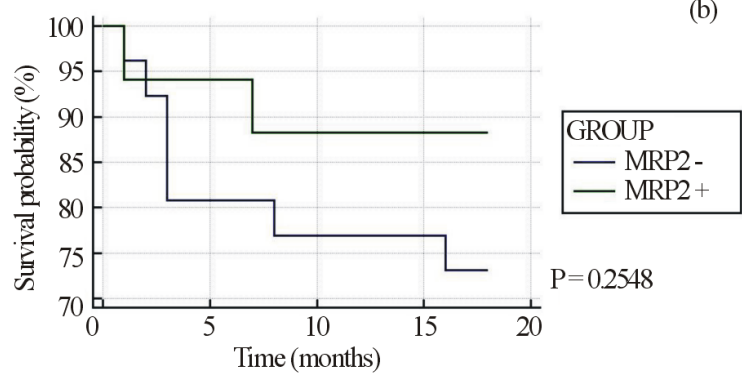

(c)

Figure 4. Survival curves and expression of ABC transporters (a) P-glycoprotein, (b) MRP1, and (c) MRP2.

\section{Discussion}

Several ABC transporters are implicated in multidrug resistance and are recognized causes for failure of cancer chemotherapy [7]-[11]. This is the case of ATP-dependent drug efflux transporter P-glycoprotein (P-gp or ABCB1) whose expression on tumor cells has been identified to be a well-recognized mechanism of cancer multidrug resistance by decreasing intracellular drug accumulation [9].

In the cases herein studied, ABC transporters expression was confined to mammary luminal cells. Other authors [14] revealed immunoexpression of P-glycoprotein in myoepithelial cells, differently from what was observed in this study. This feature probably occurred due to the use of the C219 clone by such authors-an antibody clone which is known to display cross-reactivity with a number of other proteins [15]. In order to avoid such cross-reaction, we used a more specific clone in order to produce more accurate results.

This study addressed the potential prognostic role of ABC transporters P-glycoprotein, MRP1, and MRP2 in a series of 43 canine mammary tumors. Given the function of drug transporters and their capability to extrude toxins, drugs, and physiological substrates from cells [16], a clear definition of their prognostic role is not straightforward to achieve. A possible role of ABC transporters protein expression in canine mammary cancer has previously been studied [6] [14] [17], but the results are not conclusive. In humans, data are also controversial. Some authors reported a loss of MRP1 expression in poorly differentiated histology cases, suggesting that MRP1 loss is associated with loss of differentiation [18] [19]. In contrast, an association of MRP1 and MDR1/P-gp increase with tumor stage had also been suggested [20]-[22], similarly to what was observed in this study and consequently suggesting that MRP1 and P-glycoprotein expression had an implication in disease outcome.

MRP1 and MDR1 have been shown to confer multidrug resistance in vitro in human cancer cell lines [23]-[25] and also in canine mammary cell lines [26]. Additionally, they were shown to be associated with poor patient outcomes and/or chemoresistance in different canine tumor types [27] [28] including mammary tumors [6]. In the present study, we had analyzed the protein levels of MDR1/P-gp, MRP1, and MRP2 and found that P-gP and MRP1 levels were higher in tumors with higher histological grade and regional lymph node metastasis, as well as an association with shorter survival, in line with results which characterized P-gp as a prognostic indicator in canine mammary tumors [6].

A number of studies have been carried out on the changes in MRP2 expression in human tumors including colorectal carcinoma [29], lung [30], and breast [31] cancers, which may be associated with their resistance to chemotherapeutic agents. Since MRP2 is involved in the efflux of various anti-neoplastic agents, these findings can indicate that neoplastic cells can acquire drug resistance through the increased MRP2 activity. Since there 
are no data regarding the expression of MRP2 in canine mammary tumors, it is not possible to directly relate such ABC transporter with drug resistance in the species. When it comes to prognosis, we find no relation of MRP2 with clinicopathologic features. This is in line with studies which evaluate MRP2 expression in human cancers [32] [33].

Overall, our results suggest that P-glycoprotein and MDR1 not only be promising candidate markers for a validation study on therapy outcome but also they may play a significant role in the course of canine mammary cancer progression.

\section{Acknowledgements}

B.S.S. thanks the Coordination for the Improvement of Higher Education Personnel (CAPES), Brazil, for financial support and Cleuso Cesário for his help with technical issues.

\section{References}

[1] Misdorp, W. (2001) Tumors of the Mammary Gland. In: Meuten, D.J., Ed., Tumors in Domestic Animals, Blackweel Publishing Company, Ames, 75-606.

[2] Lana, S.E., Rutteman, G.R. and Withrow, S.J. (2007) Tumors of the Mammary Gland. In: Withrow, S.J. and Vail, D.M., Eds., Withrow and MacEwen's Small Animal Clinical Oncology, 4th Edition, Saunders Elsevier, St. Louis, 619-638. http://dx.doi.org/10.1016/b978-072160558-6.50029-0

[3] Gama, A., Gärtner, F., Alves, A. and Schmitt, F. (2009) Immunohistochemical Expression of Epidermal Growth Factor Receptor (EGFR) in Canine Mammary Tissues. Research in Veterinary Science, 87, 432-437. http://dx.doi.org/10.1016/j.rvsc.2009.04.016

[4] Terragni, R., Gardini, A.C., Sabattini, S., Bettini, G., Amadori, D., Talamonti, C., Vignoli, M., Capelli, L., Saunders, J.H., Ricci, M. and Ulivi, P. (2014) EGFR, HER-2 and KRAS in Canine Gastric Epithelial Tumors: A Potential Human Model? PLOS ONE, 9, 1-7. http://dx.doi.org/10.1371/journal.pone.0085388

[5] Lee, C.-H., Kim, W.-H., Lim, J.-H., Kang, M.-S., Kim, D.-Y. and Kweon, O.-K. (2004) Mutation and Overexpression of 553 as a Prognostic Factor in Canine Mammary Tumors. Journal of Veterinary Science, 5, 63-69. http://dx.doi.org/10.1292/jvms.66.63

[6] Koltai, Z. and Valjdovich, P. (2014) Expression of Multidrug Resistance Membrane Transporter (Pgp) and p53 Protein in Canine Mammary Tumours. Acta Veterinaria Hungarica, 2, 194-204. http://dx.doi.org/10.1556/AVet.2014.002

[7] Trock, B.J., Leonessa, F. and Clarke, R. (1997) Multidrug Resistance in Breast Cancer: A Meta-Analysis of MDR1/gp170 Expression and Its Possible Functional Significance. The Journal of the National Cancer Institute, 89, 917-931. http://dx.doi.org/10.1093/jnci/89.13.917

[8] Abolhoda, A., Wilson, A.E., Ross, H., Danenberg, P.V., Burt, M. and Scotto, K.W. (1999) Rapid Activation of MDR1 Gene Expression in Human Metastatic Sarcoma after in Vivo Exposure to Doxorubicin. Clinical Cancer Research, 5, 3352-3356.

[9] Wenzel, J.J., Piehler, A. and Kaminski, W.E. (2007) ABC A-Subclass Proteins: Gatekeepers of Cellular Phospho- and Sphin-Golipid Transport. Frontiers in Bioscience, 12, 3177-3193. http://dx.doi.org/10.2741/2305

[10] Amiri-Kordestani, L., Basseville, A., Kurdziel, K., Fojo, A.T. and Bates, S.E. (2012) Targeting MDR in Breast and Lung Cancer: Discriminating Its Potential Importance from the Failure of Drug Resistance Reversal Studies. Drug Resistance Updates, 15, 50-61. http://dx.doi.org/10.1016/j.drup.2012.02.002

[11] Hedditch, E.L., Gao, B., Russel, A.J., Lu, Y., Emmanuel, C., Beesley, J., Johnatty, S.E., Chen, X., Harnett, P., George, J., Williams, R.T., Flemming, C., Lambrechts, D., Despierre, E., Lambrechts, S., Vergote, I., Karlan, B., Lester, J., Orsulic, S., Walsh, C., Fasching, P., Beckmann, M.W., Ekici, A.B., Hein, A., Matsuo, K., Hosono, S., Nakanishi, T., Yatabe, Y., Pejovic, T., Bean, Y., Heitz, F., Harter, P., Du Bois, A., Schwaab, I., Hogdall, E., Kjaer, S.K., Jensen, A., Hogdall, C., Lundvall, L., Engelholm, S.A., Brown, B., Flanagan, J., Metcalf, M.D., Siddiqui, N., Sellers, T., Fridley, B., Cunningham, J., Schidkraut, J., Iversen, E., Weber, R.P., Berchuck, A., Goode, E., Bowtee, D.D., Chenevix-Trench, G., Defazio, A., Norris, M.D., Macgregor, S., Haber, M. and Henderson, M.J. (2014) ABCA Transporter Gene Expression and Poor Outcome in Epithelial Ovarian Cancer. The Journal of the National Cancer Institute, 7, 1-11. http://dx.doi.org/10.1093/jnci/dju149

[12] Higgins, C.F. (1992) ABC Transporters: From Microorganisms to Man. Annual Review of Cell Biology, 8, 67-113. http://dx.doi.org/10.1146/annurev.cb.08.110192.000435

[13] Elston, C.W. and Ellis, I.O. (1991) Pathological Prognostic Factors in Breast Cancer. I. The Value of Histological Grade in Breast Cancer: Experience from a Large Study with Long-Term Follow-Up. Histopathology, 19, 403-410. http://dx.doi.org/10.1111/j.1365-2559.1991.tb00229.x 
[14] Kim, N.-H., Hwang, Y.-H., Im, K.-S., Kim, J.-H., Chon, S.-K., Kim, H.-Y. and Sur, J.-H. (2012) P-Glycoprotein Expression in Canine Mammary Gland Tumours Related with Myoepithelial Cells. Research in Veterinary Science, 93, 1346-1352. http://dx.doi.org/10.1016/j.rvsc.2012.04.004

[15] van den Elsen, J.M.H., Kuntz, D.A., Hoedemaeker, F.J. and Rose, D.R. (1999) Antibody C219 Recognizes an Alpha-Helical Epitope on P-Glycoprotein. Proceeding of the National Academy of Sciences of the United States of America, 96, 13679-13684. http://dx.doi.org/10.1073/pnas.96.24.13679

[16] Fletcher, J.I., Haber, M., Henderson, M.J. and Norris, M.D. (2010) ABC Transporters in Cancer: More than Just Drug Efflux Pumps. Nature Reviews Cancer, 10, 147-156. http://dx.doi.org/10.1038/nrc2789

[17] Petterino, C., Rossetti, E., Bertoncello, D., Martini, M., Zappulli, V., Bargelloni, L. and Castagnaro, M. (2006) Immunohistochemical Detection of P-Glycoprotein (Clone C494) in Canine Mammary Gland Tumours. Journal of Veterinary Medicine Series A, 53, 174-178. http://dx.doi.org/10.1111/j.1439-0442.2006.00810.x

[18] Beck, J., Bohnet, B., Brugger, D., Bader, P., Dietl, J., Scheper, R.J., Kandolf, R., Liu, C., Niethammer, D. and Gekeler, V. (1998) Multiple Gene Expression Analysis Reveals Distinct Differences between G2 and G3 Stage Breast Cancers and Correlations of PKC Eta with MDR1, MRP and LRP Gene Expression. British Journal of Cancer, 77, 87-91. http://dx.doi.org/10.1038/bjc.1998.13

[19] Ferrero, J.M., Etienne, M.C., Formento, J.L., Francoual, M., Rostagno, P., Peyrottes, I., Ettore, F., Teissier, E., Leblanc-Talent, P., Namer, M. and Milano, G. (2000) Application of an Original RT PCR-ELISA Multiplex Assay for MDR1 and MRP, along with p53 Determination in Node-Positive Breast Cancer Patients. British Journal of Cancer, 82, 171-177.

[20] Filipitis, M., Suchomel, R.W., Dekan, G., Haider, K., Valdimarsson, G., Depisch, D. and Pirker, R. (1996) MRP and MDR1 Gene Expression in Primary Breast Carcinomas. Clinical Cancer Research, 2, 1231-1237. http://dx.doi.org/10.1016/0959-8049(96)84850-7

[21] Nooter, K., Brutel de la Riviere, G., Look, M.P., van Wingerden, K.E., Henzen-Logmans, S.C., Scheper, R.J., Flens, M.J., Klijn, J.G., Stoter, G. and Foekens, J.A. (1997) The Prognostic Significance of Expression of the Multidrug Resistance-Associated Protein (MRP) in Primary Breast Cancer. British Journal of Cancer, 76, 486-493. http://dx.doi.org/10.1038/bjc.1997.414

[22] Sun, S.-S., Hsieh, J.-F., Tsai, S.-C., Ho, Y.-J., Lee, J.-K. and Kao, C.-H. (2000) Expression of Mediated P-Glycoprotein Multidrug Resistance Related to Tc-99m MIBI Scintimammography Results. Cancer Letters, 153, 95-100. http://dx.doi.org/10.1016/S0304-3835(00)00356-6

[23] Goto, H., Keshelava, N., Matthay, K.K., Lukens, J.N., Gerbing, R.B., Stram, D.O., Seeger, R.C. and Reynolds, C.P. (2000) Multidrug Resistance-Associated Protein 1 (MRP1) Expression in Neuroblastoma Cell Lines and Primary Tumors. Medical and Pediatric Oncology, 35, 619-622. http://dx.doi.org/10.1002/1096-911X(20001201)35:6<619::AID-MPO28>3.0.CO;2-H

[24] Ferreira, M.J.U., Gyemant, N., Madureira, A.M., Tanaka, M., Koos, K., Didziapetris, R. and Molnar, J. (2005) The Effects of Jatrophane Derivatives on the Reversion of MDR1- and MRP-Mediated Multidrug Resistance in the MDA-MB-231 (HTB-26) Cell Line. Anticancer Research, 25, 4173-4178.

[25] Nakai, E., Park, K., Yawata, T., Chihara, T., Kumazawa, A., Nakabavashi, H. and Shimizu, K. (2009) Enhanced MDR1 Expression and Chemoresistance of Cancer Stem Cells Derived from Glioblastoma. Cancer Investigation, 27, 901-908. http://dx.doi.org/10.3109/07357900801946679

[26] Pawlowski, K.M., Mucha, J., Majchrzak, K., Motyl, T. and Król, M. (2013) Expression and Role of PGP, BCRP, MRP1 and MRP3 in Multidrug Resistance of Canine Mammary Cancer Cells. BMC Veterinary Research, 9, 119. http://dx.doi.org/10.1186/1746-6148-9-119

[27] Gaspar, L.F.J., Ferreira, I., Colodel, M., Brandão, C.V.S. and Rocha, N.S. (2010) Spontaneous Canine Transmissible venereal Tumor: Cell Morphology and Influence on P-Glycoprotein Expression. Turkish Journal of Veterinary Animal Science, 34, 447-454.

[28] Teng, S.-H., Hsu, W.-L., Chiu, C.-Y., Wong, M.-L. and Chang, S.-C. (2012) Overexpression of P-Glycoprotein, STAT3, Phospho-STAT3 and KIT in Spontaneous Canine Cutaneous Mast Cell Tumours before and after Prednisolone Treatment. The Veterinary Journal, 193, 551-556. http://dx.doi.org/10.1016/j.tvjl.2012.01.033

[29] Hinoshita, E., Uchiumi, T., Taguchi, K., Kinukawa, N., Tsuneyoshi, M., Maehara, Y., Sugimachi, K. and Kuwano, M. (2000) Increased Expression of an ATP-Binding Cassette Superfamily Transporter, Multidrug Resistance Protein 2, in Human Colorectal Carcinomas. Clinical Cancer Research, 6, 2401-2407.

[30] Young, L.C., Campling B.G., Cole, S.P., Deeley, R.G. and Gerlach, J.H. (2001) Multidrug Resistance Proteins MRP3, MRP1, and MRP2 in Lung Cancer: Correlation of Protein Levels with Drug Response and Messenger RNA Levels. Clinical Cancer Research, 7, 1798-1804

[31] Choi, H.-K., Yang, J.-W., Roh, S.-H., Han, C.-Y. and Kang, K.-W. (2007) Induction of Multidrug Resistance Asso- 
ciated Protein 2 in Tamoxifen-Resistant Breast Cancer Cells. Endocrine-Related Cancer, 14, 293-303. http://dx.doi.org/10.1677/ERC-06-0016

[32] Ota, S., Ishii, G., Goto, K., Kubota, K., Kim, Y.-H., Kojika, M., Murata, Y., Yamazi, M., Nishiwaki, Y., Eguchi, K. and Ochiai, A. (2009) Immunohistochemical Expression of BCRP and ERCC1 in Biopsy Specimen Predicts Survival in Advanced Non-Small-Cell Lung Cancer Treated with Cisplatin-Based Chemotherapy. Lung Cancer, 64, 98-104. http://dx.doi.org/10.1016/j.lungcan.2008.07.014

[33] Tian, C., Ambrosone, C.B., Darcy, K.M., Krivak, T.C., Armstrong, D.K., Bookman, M.A., Davis, W., Zhao, H., Moysich, K., Gallion, H. and DeLoia, J.A. (2012) Common Variants in ABCB1, ABCC2 and ABCG2 Genes and Clinical Outcomes among Women with Advanced Stage Ovarian Cancer Treated with Platinum and Taxane-Based Chemotherapy: A Gynecologic Oncology Group Study. Gynecologic Oncology, 124, 575-581.

http://dx.doi.org/10.1016/j.ygyno.2011.11.022 